\title{
Estratificação ambiental na avaliação de genótipos de feijoeiro-comum tipo Carioca em Goiás e no Distrito Federal
}

\author{
Helton Santos Pereira ${ }^{(1)}$, Leonardo Cunha Melo ${ }^{(1)}$, Luís Cláudio de Faria ${ }^{(1)}$, \\ Maria José Del Peloso(1) e Adriane Wendland ${ }^{(1)}$
}

(1)Embrapa Arroz e Feijão, Rodovia GO-462, Km 12, Caixa Postal 179, CEP 75375-000 Santo Antônio de Goiás, GO. E-mail: helton@cnpaf.embrapa.br, leonardo@cnpaf.embrapa.br, mjpeloso@cnpaf.embrapa.br, Icfaria@cnpaf.embrapa.br, adrianew@cnpaf.embrapa.br

\begin{abstract}
Resumo - O objetivo deste trabalho foi realizar a estratificação ambiental nos Estado de Goiás e no Distrito Federal para a avaliação da produtividade de grãos de genótipos de feijoeiro-comum tipo Carioca, e comparar a eficiência de diferentes métodos de estratificação ambiental. Foram realizados 25 ensaios em blocos ao acaso, com três repetições, nas épocas de semeadura das águas e do inverno, nos anos de 2003 e 2004. Os ensaios foram compostos por 16 genótipos de grãos tipo Carioca. A estratificação ambiental foi realizada por meio de quatro metodologias: tradicional de Lin; percentagem simples da interação de genótipos com os locais dois a dois, de Cruz e Castoldi; correlação de Pearson para os pares de locais; e método da ecovalência de Wricke. Os locais identificados como similares em pelo menos três metodologias foram considerados pouco informativos, e eles foram os seguintes municípios do Estado de Goias: Anápolis, Santo Antônio de Goiás, Goiatuba e Urutaí, nas safras das águas/2003 e águas/2004, inverno/2003 e inverno/2004, respectivamente. Nenhum dos locais foi identificado como pouco informativo em pelo menos duas safras e, portanto, nenhum deles foi eliminado da rede de avaliação de genótipos de feijoeiro-comum tipo Carioca. Os locais utilizados em todas as safras (Rio Verde, GO, e Planaltina, DF) não foram identificados como pouco informativos em nenhuma delas e, portanto, são indicados para a avaliação de genótipos de feijoeiro-comum. Os métodos de Lin e da ecovalência foram os mais indicados para identificação de locais pouco informativos.
\end{abstract}

Termos para indexação: Phaseolus vulgaris, ecovalência, interação genótipo por ambiente, local de teste.

\section{Environmental stratification in Carioca common bean genotype evaluation in Goiás and Distrito Federal, Brazil}

\begin{abstract}
The objective of this study was to perform the environmental stratification in the states of Goiás and Distrito Federal for grain yield evaluation of Carioca common bean genotypes, and to compare the efficiency of different methods of environmental stratification. Twenty-five trials were carried out in a randomized block design with three replications, both in the rainy and in the winter sowing seasons, in 2003 and 2004. The trials were composed of 16 genotypes with Carioca grain type. The environmental stratification was performed through four methodologies: traditional Lin; Cruz \& Castoldi's estimate of the simple percentage of the genotypes by location interactions; estimate of Pearson's correlation for pairs of locals; and the Wricke's ecovalence method. Locations identified as similar by at least three of the methodologies were considered poor-informative, and they were the following Goiás state municipalities: Anápolis, Santo Antônio de Goiás, Goiatuba and Urutaí, in the rainy/2003, rainy/2004, winter/2003 and winter/2004 growing seasons, respectively. None of the locations was identified as poor-informative in at least two seasons and, therefore, none of them was eliminated from the evaluation network of Carioca common bean genotypes. The locations used in all growing seasons (Rio Verde, GO, and Planaltina, DF) were not identified as poor-informative in none of them and, therefore, they were indicated for evaluation of Carioca common bean genotypes. The methods of Lin and Wricke were the most indicated to identify poor-informative locations.
\end{abstract}

Index terms: Phaseolus vulgaris, ecovalence, genotype by environment interaction, test location.

\section{Introdução}

No Brasil, o feijoeiro-comum é submetido a diferentes condições ambientais, pois ele é cultivado em vários estados, em diferentes épocas de semeadura (águas, seca e inverno) e sistemas de cultivo, que variam desde a agricultura de subsistência, com baixo uso de insumos, até a agricultura empresarial, de alta tecnologia. Nessa condição, espera-se uma acentuada interação genótipos x ambientes (GxA), especialmente quanto à produção de grãos, o que foi comprovado em vários trabalhos de pesquisa com a cultura no país

Pesq. agropec. bras., Brasília, v.45, n.6, p.554-562, jun. 2010 
(Carbonell et al., 2004; Melo et al., 2007; Pereira et al., 2009).

A interação GxA pode ser composta de duas partes. A primeira, denominada simples, representa a resposta diferencial dos genótipos aos ambientes, sem que ocorra alteração na classificação dos genótipos. A segunda parte, denominada complexa, é dada pela menor correlação entre o desempenho dos genótipos nos ambientes e é causada pela alteração da ordem de classificação dos genótipos nesses ambientes (Cruz \& Regazzi, 2001).

A interação GxA tem inúmeras implicações em um programa de melhoramento e, na etapa de avaliação de linhagens para indicação de novas cultivares aos agricultores, sua importância torna-se mais evidente. As avaliações das linhagens devem ser realizadas em redes de ensaios, para que se estime seu valor de cultivo e uso, o que viabiliza sua indicação para cultivo nas regiões onde foram testadas.

O Estado de Goiás e o Distrito Federal respondem por cerca de $10 \%$ da produção nacional de feijão, o que representou 266.806 toneladas, em 2008 (Feijão, 2010). Essa produção está concentrada nas épocas de semeadura das águas (de outubro a dezembro) (40\%) e de inverno (de abril a julho) (49\%), enquanto a época da seca representa apenas $11 \%$ da produção, principalmente pela ocorrência do vírus mosaico-dourado do feijoeiro (Bean Golden Mosaic Virus), que praticamente inviabiliza a produção de feijão nessa região e nessa época (Melo et al., 2005). A produtividade média de $2.296 \mathrm{~kg} \mathrm{ha}^{-1}$, obtida nesses estados, é bastante superior à média nacional de $1.233 \mathrm{~kg} \mathrm{ha}^{-1}$.

A implantação da rede de avaliação é um procedimento bastante trabalhoso e oneroso, o que faz com que, nos programas de melhoramento, se busque verificar se os locais de avaliação geram informações complementares, pois a redundância entre os locais deve ser eliminada. Esta similaridade pode ser examinada por procedimentos de estratificação ambiental. No entanto, a classificação entre os genótipos para a produção de grãos pode ser semelhante entre dois locais, porém com causas distintas. Portanto, antes de se descartarem locais aparentemente redundantes, é necessário examinar as causas da semelhança entre eles, como a presença regular de algum tipo de estresse, para que os locais que tragam informações diferentes, não sejam eliminados. Como os locais de condução de ensaios mudam constantemente, deve-se realizar a estratificação ambiental regularmente. Deve-se, também, lembrar que a identificação de padrões de similaridade entre locais, para a cultura do feijoeiro-comum, deve ser consistente ao longo do tempo, em diferentes safras, para que seja obtida informação mais segura sobre a definição dos locais em que as linhagens devem ser testadas.

Entre os métodos de estratificação ambiental, o de Lin (1982) procura formar subgrupos homogêneos em que a interação GxA seja não significativa. Quando a interação GxA é significativa entre pares de ambientes, pode-se utilizar o método de Cruz \& Castoldi (1991), que identifica o percentual relativo à parte simples da interação, e também as correlações de Pearson e de Spearman. O método de Murakami \& Cruz (2004) é baseado na técnica multivariada de análise de fatores e reúne a estratificação ambiental e a análise de estabilidade. A estimativa da ecovalência (Wricke, 1965), utilizada inicialmente para medir a contribuição de cada genótipo para a interação GxA, também pode ser utilizada para avaliar a contribuição de cada ambiente para a interação, por meio da decomposição da soma de quadrados da interação em frações relacionadas a esses ambientes e, dessa forma, identificar locais pouco informativos.

$\mathrm{Na}$ cultura do feijoeiro-comum, alguns trabalhos de estratificação ambiental foram realizados nos estados de Minas Gerais (Oliveira et al., 2005), São Paulo (Carbonell \& Pompeu, 1997) e Santa Catarina (Bertoldo et al., 2009). Entretanto, para o Estado de Goiás e para o Distrito Federal, ainda não foram encontrados relatos com essa cultura.

O objetivo deste trabalho foi aplicar procedimentos de estratificação ambiental para identificar possíveis locais pouco informativos na avaliação de genótipos de feijoeiro-comum tipo Carioca, no Estado de Goiás e no Distrito Federal, e comparar quatro metodologias de estratificação ambiental.

\section{Material e Métodos}

Os ensaios foram conduzidos nos anos de 2003 e 2004, em 25 ambientes no Estado de Goiás e no Distrito Federal, nas épocas das águas e do inverno (onze locais, duas épocas de semeadura e dois anos), em blocos ao acaso, com parcelas de quatro linhas de quatro metros de comprimento e três repetições, conforme as normas do Ministério da Agricultura e Pecuária, Registro Nacional de Cultivares (Brasil, 2006). Cada ensaio 
foi constituído de 16 genótipos do grupo Carioca, dos quais doze linhagens (CNFC 9458, CNFC 9471, CNFC 9484, CNFC 9494, CNFC 9500, CNFC 9504, CNFC 9506, CNFC 9518, CNFE 8009, Carioca 11, CNFC 9435 e CNFC 9461) e quatro testemunhas (Pérola, Iapar 81, Carioca Pitoco e Magnífico). Entre esses genótipos, a linhagem CNFC 9435 e a testemunha Carioca Pitoco apresentam ciclo semi-precoce, com 75 a 84 dias da emergência à maturação fisiológica, enquanto os demais genótipos apresentam ciclo normal de 85 a 94 dias.

Os dados de produtividade de cada ensaio foram coletados nas duas linhas centrais e foram submetidos à análise de variância, tendo-se considerado o efeito de genótipos como fixo e o efeito de blocos como aleatório. Em seguida, foram realizadas análises conjuntas dos ensaios para cada safra, tendo-se considerado os efeitos de genótipos e locais como fixos. Nas análises em que a razão entre o maior e o menor quadrado médio do resíduo foi superior a sete - indicativo de que as variâncias residuais não foram homogêneas (Gomes, 2000) -, procedeu-se ao ajuste dos graus de liberdade do erro e da interação GxA, conforme o método de Cochran (1954).

As análises de estratificação ambiental foram realizadas para cada safra (combinação de época de semeadura e ano), com o aplicativo Genes (Cruz, 2001), pelos métodos: tradicional, proposto por Lin (1982); método de Cruz \& Castoldi (1991) (percentagem associada à parte simples da interação); estimativa de correlação de Pearson; e método da ecovalência (Wricke, 1965).

O método de Lin (1982) consiste em estimar a soma de quadrados para a interação entre genótipos e pares de ambientes e, posteriormente, agrupar os ambientes cuja interação é não significativa. O método prossegue com a estimação da soma de quadrados entre genótipos e grupos de três ambientes, e é empregado o teste F para se avaliar a possibilidade de formação de novo grupo. Assim, são formados grupos de $\mathrm{x}$ ambientes, em que a interação é não significativa e, consequentemente, estes são considerados os ambientes menos informativos.

O método de Cruz \& Castoldi (1991) consiste em separar a interação GxA entre pares de ambientes em duas partes. A primeira, denominada simples, é proporcionada pela diferença de variabilidade entre genótipos nos ambientes, e a segunda, denominada complexa, é gerada pela baixa correlação entre os locais em razão do desempenho irregular dos genótipos, o que indica inconsistência da superioridade de genótipos com a variação ambiental (Cruz \& Regazzi, 2001). A ocorrência de maior parte da interação atribuída à parte simples indica que os ambientes são similares. Foram considerados similares os locais com percentagem simples da interação acima de $50 \%$, pois quanto maior essa percentagem, menos informativos são os locais.

Foram estimadas as correlações de Pearson entre as médias dos genótipos nos pares de locais, que foram considerados similares quando a respectiva correlação foi significativa. O par de locais com maior estimativa de correlação foi considerado o menos informativo.

A ecovalência, utilizada inicialmente para medir a contribuição de cada genótipo para a interação GxA (Wricke, 1965), no presente trabalho serviu para estimar a contribuição de cada local para a interação GxA. Para isso, decompôs-se a soma de quadrados da interação GxA nas partes devidas a cada local, segundo a expressão abaixo:

$$
\omega_{\mathrm{j}}=\mathrm{r} \sum_{\mathrm{i}}\left(\mathrm{Y}_{\mathrm{ij}}-\overline{\mathrm{Y}}_{\mathrm{j}}-\overline{\mathrm{Y}}_{\mathrm{i} .}+\overline{\mathrm{Y}}_{. .}\right)^{2}
$$

em que: $r$ são as repetições; $Y_{i j}$ é a média do genótipo i no local j; $\bar{Y}_{i}$ é a média do genótipo $\mathrm{i} ; \overline{\mathrm{Y}}_{\mathrm{j}}$ é a média do

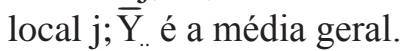

Os locais com menor estimativa de ecovalência foram considerados pouco informativos. Foi também estimada a correlação de Pearson, entre a estimativa de ecovalência e a média de cada local, em cada safra.

Para a identificação do local menos informativo, em cada safra, foram considerados os resultados dos métodos em conjunto, ou seja, locais classificados como pouco informativos conforme Wricke (1965), ou grupos/pares de locais identificados como pouco informativos nos outros métodos. Locais que apresentaram essas características, em pelo menos três metodologias, foram considerados os menos informativos.

Para a identificação dos locais pouco informativos ao longo do tempo, que poderiam consequentemente ser eliminados, consideraram-se os locais que se repetiram em pelo menos duas das safras como pouco informativos.

Para a comparação dos métodos utilizados, observouse quantas vezes o local menos informativo, em cada safra, foi identificado em cada um dos métodos. Métodos que identificaram o local menos informativo 
mais vezes, nas diferentes safras, foram considerados mais eficientes.

\section{Resultados e Discussão}

As médias de produtividade dos ensaios variaram de $1.091 \mathrm{~kg} \mathrm{ha}^{-1}$ a $3.853 \mathrm{~kg} \mathrm{ha}^{-1}$, o que mostra que houve grande variação nas condições em que os ensaios foram conduzidos (Tabela 1). Este fato pode ser atribuído, em parte, à grande diversidade na distribuição geográfica dos locais utilizados na avaliação, com altitude de 448 a $1.189 \mathrm{~m}$; latitude de $15^{\circ} 27^{\prime}$ a $18^{\circ} 25^{\prime} \mathrm{S}$; e longitude de $47^{\circ} 20^{\prime}$ a $50^{\circ} 55^{\prime} \mathrm{W}$. Isto, certamente, reflete as diferenças climáticas entre os locais utilizados na avaliação. Os valores do coeficiente de variação variaram de 9 a $25 \%$, indicando boa precisão experimental.

Em todas as análises conjuntas, foram detectadas diferenças significativas entre locais, o que evidencia a possibilidade de realização das análises de estratificação ambiental (Tabela 2). Quanto à fonte de variação de genótipos, houve diferença significativa em todas as

Tabela 1. Informações geográficas dos locais avaliados, e resumos das análises de variância individuais dos 25 ensaios com genótipos de feijoeiro-comum tipo Carioca, conduzidos nas águas e no inverno, no Estado de Goiás e no Distrito Federal, em 2003 e 2004.

\begin{tabular}{|c|c|c|c|c|c|c|c|}
\hline Local & Altitude & Latitude & Longitude & $\mathrm{QMe}$ & Média $\left(\mathrm{kg} \mathrm{ha}^{-1}\right)$ & CV (\%) & QMg \\
\hline & \multicolumn{7}{|c|}{ Águas de 2003} \\
\hline Planaltina, DF & 944 & $15^{\circ} 27^{\prime}$ & $47^{\circ} 36^{\prime}$ & 189.169 & 2.106 & 21 & ns \\
\hline Rio Verde, GO & 715 & $17^{\circ} 47^{\prime}$ & $50^{\circ} 55^{\prime}$ & 88.291 & 1.891 & 16 & $* *$ \\
\hline Ipameri, GO & 764 & $17^{\circ} 43^{\prime}$ & $48^{\circ} 09^{\prime}$ & 127.779 & 2.819 & 13 & $* *$ \\
\hline Anápolis, GO & 1.018 & $16^{\circ} 19^{\prime}$ & $48^{\circ} 57^{\prime}$ & 69.003 & 1.369 & 19 & $* *$ \\
\hline \multirow[t]{2}{*}{ Formosa, GO } & 916 & $15^{\circ} 32^{\prime}$ & $47^{\circ} 20^{\prime}$ & 81.362 & 1.483 & 19 & $* *$ \\
\hline & \multicolumn{7}{|c|}{ Águas de 2004} \\
\hline Planaltina, DF & 944 & $15^{\circ} 27^{\prime}$ & $47^{\circ} 36^{\prime}$ & 102.792 & 3.480 & 9 & $* *$ \\
\hline Anápolis, GO & 1.018 & $16^{\circ} 19^{\prime}$ & $48^{\circ} 57^{\prime}$ & 107.186 & 2.307 & 14 & $* *$ \\
\hline Santo Antônio de Goiás, GO & 823 & $16^{\circ} 29^{\prime}$ & $49^{\circ} 18^{\prime}$ & 22.412 & 1.091 & 14 & $* *$ \\
\hline Rio Verde, GO & 715 & $17^{\circ} 47^{\prime}$ & $50^{\circ} 55^{\prime}$ & 145.613 & 2.708 & 14 & $* *$ \\
\hline Morrinhos, GO & 771 & $17^{\circ} 43^{\prime}$ & $49^{\circ} 05^{\prime}$ & 97.059 & 1.687 & 18 & ns \\
\hline Urutaí, GO & 807 & $17^{\circ} 27^{\prime}$ & $48^{\circ} 12^{\prime}$ & 29.728 & 1.755 & 10 & $* *$ \\
\hline \multirow[t]{2}{*}{ Cristalina, GO } & 1.189 & $16^{\circ} 46^{\prime}$ & $47^{\circ} 36^{\prime}$ & 36.981 & 1.286 & 15 & $* *$ \\
\hline & \multicolumn{7}{|c|}{ Inverno de 2003} \\
\hline Planaltina, DF & 944 & $15^{\circ} 27^{\prime}$ & $47^{\circ} 36^{\prime}$ & 91.425 & 2.359 & 13 & * \\
\hline Goiatuba, GO & 774 & $18^{\circ} 00^{\prime}$ & $49^{\circ} 21^{\prime}$ & 53.005 & 1.685 & 14 & $* *$ \\
\hline Santo Antônio de Goiás, GO & 823 & $16^{\circ} 29^{\prime}$ & $49^{\circ} 18^{\prime}$ & 86.877 & 1.827 & 16 & $* *$ \\
\hline Rio Verde, GO & 715 & $17^{\circ} 47^{\prime}$ & $50^{\circ} 55^{\prime}$ & 117.006 & 2.710 & 13 & $* *$ \\
\hline Urutaí, GO & 807 & $17^{\circ} 27^{\prime}$ & $48^{\circ} 21^{\prime}$ & 95.784 & 2.452 & 13 & $* *$ \\
\hline \multirow[t]{2}{*}{ Cristalina, GO } & 1.189 & $16^{\circ} 46^{\prime}$ & $47^{\circ} 36^{\prime}$ & 569.989 & 3.479 & 22 & $* *$ \\
\hline & \multicolumn{7}{|c|}{ Inverno de 2004} \\
\hline Planaltina, DF & 944 & $15^{\circ} 27^{\prime}$ & $47^{\circ} 36^{\prime}$ & 263.357 & 3.853 & 13 & ns \\
\hline Anápolis, GO & 1.018 & $16^{\circ} 19^{\prime}$ & $48^{\circ} 57^{\prime}$ & 318.029 & 2.843 & 20 & ns \\
\hline Santo Antônio de Goiás, GO & 823 & $16^{\circ} 29^{\prime}$ & $49^{\circ} 18^{\prime}$ & 139.165 & 2.729 & 14 & ns \\
\hline Rio Verde, GO & 715 & $17^{\circ} 47^{\prime}$ & $50^{\circ} 55^{\prime}$ & 91.255 & 3.075 & 10 & $*$ \\
\hline Itumbiara, GO & 448 & $18^{\circ} 25^{\prime}$ & $49^{\circ} 12^{\prime}$ & 111.910 & 1.835 & 18 & $* *$ \\
\hline Morrinhos, GO & 771 & $17^{\circ} 43^{\prime}$ & $49^{\circ} 05^{\prime}$ & 201.545 & 1.745 & 25 & ns \\
\hline Cristalina, GO & 1.189 & $16^{\circ} 46^{\prime}$ & $47^{\circ} 36^{\prime}$ & 311.833 & 2.551 & 22 & $* *$ \\
\hline
\end{tabular}

*e**Significativos a 1 e a 5\% de probabilidade, respectivamente. QMe, quadrado médio do erro; QMg, significância do quadrado médio de genótipos.

Tabela 2. Resumo das análises conjuntas de variância por safra, quanto à produtividade de grãos $\left(\mathrm{kg} \mathrm{ha}^{-1}\right)$ de genótipos de feijoeiro comum tipo Carioca, nas duas épocas de semeadura, em 2003 e 2004, no Estado de Goiás e no Distrito Federal.

\begin{tabular}{|c|c|c|c|c|c|c|c|c|}
\hline \multirow[t]{3}{*}{ Fonte de variação } & \multicolumn{4}{|c|}{ Águas } & \multicolumn{4}{|c|}{ Inverno } \\
\hline & \multicolumn{2}{|r|}{2003} & \multicolumn{2}{|r|}{2004} & \multicolumn{2}{|r|}{2003} & \multicolumn{2}{|r|}{2004} \\
\hline & GL & Quadrado médio & GL & Quadrado médio & GL & Quadrado médio & GL & Quadrado médio \\
\hline Repetição/locais & 10 & 163.839 & 14 & 284.345 & 12 & 459.237 & 14 & 356.911 \\
\hline Locais(L) & 4 & $16.041 .314^{* *}$ & 6 & $34.111 .620^{* *}$ & 5 & $20.179 .813^{* *}$ & 6 & $25.313 .008^{* *}$ \\
\hline Genótipos $(\mathrm{G})$ & 15 & $756.158^{* *}$ & 15 & $993.533^{* *}$ & 15 & $849.282^{* *}$ & 15 & $834.000^{* *}$ \\
\hline $\mathrm{G} \times \mathrm{L}$ & 60 & $305.032^{* *}$ & 90 & $380.853^{* *}$ & $(39)^{(1)}$ & $1.130 .078^{* *}$ & 90 & $385.995^{* *}$ \\
\hline Resíduo & 150 & 111.121 & 210 & 77.396 & $(84)^{(1)}$ & 362.173 & 210 & 205.299 \\
\hline Total & 239 & - & 335 & - & 287 & - & 335 & - \\
\hline Média & - & 1.933 & - & 2.045 & - & 2.419 & - & 2.662 \\
\hline CV (\%) & - & 17 & - & 14 & - & 25 & - & 17 \\
\hline
\end{tabular}

${ }^{(1)}$ Graus de liberdade da interação e do erro ajustados (Cochran, 1954). **Significativo a $1 \%$ de probabilidade pelo teste $\mathrm{F}$. 
safras, confirmando a variabilidade entre os genótipos avaliados. A interação GxA, que esteve presente em todas as safras, reforça a possibilidade de realização da estratificação ambiental. Conforme o esperado, as médias gerais foram menores na época de semeadura das águas do que no inverno e confirmam que, nessa última época, é obtida maior produtividade.

A análise de estratificação pelo método de Lin (1982), na safra das águas/2003, formou dois grupos de locais (Tabela 3). Os locais identificados como semelhantes foram Anápolis, GO, e Formosa, GO, em um primeiro grupo, e Rio Verde, GO e Planaltina, DF, em um segundo grupo .Apenas o par Anápolis-Formosa mostrou alta porcentagem da interação GxA atribuída à parte simples $(75 \%)$, e também alta estimativa de correlação de Pearson $(0,86)$, o que confirma a semelhança na classificação dos genótipos nesses locais (Tabela 4). A análise de ecovalência mostrou que, na safra das águas/2003, o local com menor contribuição para a interação foi Anápolis (8\%), enquanto Formosa mostrou a maior contribuição para a interação (34\%) (Tabela 5). Assim, considerando-se os métodos em conjunto, Anápolis foi considerado o local menos informativo nessa safra.

Na safra das águas/2004, o método de Lin (1982) agrupou os locais Morrinhos, GO, e Urutaí, GO, como semelhantes (Tabela 3). Esse par de locais apresentou também a maior percentagem de interação simples $(64,8 \%)$ e alta estimativa de correlação de Pearson $\left(0,66^{* *}\right)$ (Tabela 4). Os locais Rio Verde e Urutaí foram identificados como semelhantes, por apresentarem percentagem simples da interação GxA acima de 50\%,(57,1\%) e também correlação de Pearson significativa $\left(0,55^{*}\right)$. O par de locais Rio Verde e Morrinhos também apresentou estimativa de correlação de Pearson significativa $(0,52 *)$. As estimativas de ecovalência para os locais Morrinhos $(6 \%)$ e Urutaí (8\%) indicaram que, na safra das águas/2004, esses foram os locais menos informativos, segundo esse método, e que Rio Verde foi o local que apresentou a maior contribuição para a interação GxA (Tabela 5). Considerando-se os resultados dos quatro métodos em conjunto, Morrinhos e Urutaí sempre foram agrupados como semelhantes, e Urutaí ainda apresentou-se semelhante a Rio Verde em dois outros métodos, o que fez com que fosse considerado o local menos informativo nessa safra.

Na safra do inverno/2003, o método de Lin (1982) formou dois grupos de locais semelhantes (Tabela 3): Rio Verde e Goiatuba, GO; e Santo Antônio de Goiás, GO, ePlanaltina. Nenhum dos pares delocais apresentou alta percentagem simples da interação GxA nessa safra (Tabela 4). Pelas estimativas de correlação de Pearson, Rio Verde e Goiatuba foram identificados como semelhantes $\left(0,51^{*}\right)$. As estimativas de ecovalência foram menores para Goiatuba $(8 \%)$ do que para os demais locais, e a maior porcentagem foi obtida para Cristalina, GO (Tabela 5). Assim, pode-se inferir que o local menos informativo foi Goiatuba, pois além de ser agrupado com Rio Verde pelo método de Lin (1982) e pela correlação de Pearson, apresentou a menor estimativa de ecovalência na safra de inverno/2003.

$\mathrm{Na}$ safra do inverno/2004, o método de Lin (1982) formou um grupo de locais com seis dos sete locais avaliados (Tabela 3). Apenas Cristalina não foi incluída nesse grupo e também não formou grupo com nenhum outro local. Os outros métodos detectaram alta percentagem de interação simples para o par Santo Antônio de Goiás e Cristalina, e nenhum dos pares mostrou correlação de Pearson significativa (Tabela 4).

Tabela 3. Agrupamentos dos locais com interação genótipos x locais não significativa por safra, conforme Lin (1982), e respectivos quadrados médios da interação genótipos x locais $\left(\mathrm{QM}_{\mathrm{GxL}}\right), \mathrm{F}$ calculado $\left(\mathrm{F}_{\mathrm{cal}}\right)$ e $\mathrm{F}$ tabelado $\left(\mathrm{F}_{\mathrm{tab}}\right)$, a $5 \%$ de probabilidade.

\begin{tabular}{|c|c|c|c|c|}
\hline Grupo & Locais & $\mathrm{QM}_{\mathrm{GXL}}$ & $\mathrm{F}_{\mathrm{cal}}$ & $\mathrm{F}_{\text {tab }}$ \\
\hline & Águas de 2003 & & & \\
\hline I & Anápolis, GO e Formosa, GO & 37.620 & 1,02 & 1,73 \\
\hline II & Rio Verde, GO e Planaltina, DF & 59.687 & 1,61 & 1,73 \\
\hline & Águas de 2004 & & & \\
\hline$\underline{I}$ & Morrinhos, GO e Urutaí, GO & 26.180 & 1,01 & 1,71 \\
\hline & Inverno de 2003 & & & \\
\hline I & Rio Verde, GO e Goiatuba, GO & 67.095 & 1,19 & 1,72 \\
\hline II & Santo Antônio de Goiás, GO e Planaltina, DF & 96.752 & 1,71 & 1,72 \\
\hline & Inverno de 2004 & & & \\
\hline$\underline{I}$ & Anápolis, Santo Antônio de Goiás, GO Rio Verde, GO Itumbiara, GO Morrinhos, GO e Planaltina, DF & 80.775 & 1,18 & 1,35 \\
\hline
\end{tabular}


A análise de ecovalência identificou Cristalina como o local de maior contribuição para a interação GxA, e Santo Antônio de Goiás, Rio Verde, Itumbiara e Morrinhos como locais de pequena contribuição para a interação $(6 \%, 6 \%, 7 \%$ e $8 \%$, respectivamente) (Tabela 5). Assim, o local considerado menos informativo nessa safra foi Santo Antônio de Goiás.

Como as condições ambientais variam ao longo dos anos, a eliminação de um local de uma rede de ensaios, pelo fato de ser identificado como pouco informativo em apenas uma safra, pode ser precipitada. Portanto, esses locais devem ser identificados em diferentes safras ao longo do tempo. Em síntese, os locais identificados como pouco informativos, nas respectivas safras, foram: Anápolis (águas/2003), Urutaí (águas/2004), Goiatuba (inverno/2003) e Santo Antônio de Goiás (inverno/2004). Isso indica que os locais avaliados, no Estado de Goiás e no Distrito Federal, são informativos e que nenhum deve ser eliminado da rede de avaliação de feijoeiro-comum tipo Carioca, já que, no máximo, foram considerados pouco informativos em apenas uma safra.

Entretanto, é importante mencionar que nem todos os locais foram repetidos em cada safra, o que diminui a chance de identificação de locais menos informativos. Essa variação entre os locais, de uma safra para

Tabela 4. Estimativas da percentagem simples da interação genótipos $x$ ambientes (\%SGA) e da correlação de Pearson $\left(r_{p}\right)$ entre os pares de locais de avaliação $\left(\mathrm{A}_{1}\right.$ e $\left.\mathrm{A}_{2}\right)$ de genótipos de feijoeiro-comum tipo Carioca, por safra, em ensaios conduzidos no Estado de Goiás e no Distrito Federal, em 2003 e $2004^{(1)}$.

\begin{tabular}{|c|c|c|c|c|c|c|c|c|c|c|c|}
\hline \multicolumn{6}{|c|}{ Inverno } & \multicolumn{6}{|c|}{ Águas } \\
\hline $\mathrm{A}_{1}$ & $\mathrm{~A}_{2}$ & SGA $(\%)$ & $\mathrm{A}_{1}$ & $\mathrm{~A}_{2}$ & $r_{p}$ & $\mathrm{~A}_{1}$ & $\mathrm{~A}_{2}$ & SGA $(\%)$ & $\mathrm{A}_{1}$ & $\mathrm{~A}_{2}$ & $r_{p}$ \\
\hline \multicolumn{12}{|c|}{ Safra 2003} \\
\hline 6 & 10 & 38,5 & 3 & 10 & $0,51^{*}$ & 1 & 9 & 75,5 & 1 & 9 & $0,86^{* *}$ \\
\hline 3 & 10 & 34,3 & 3 & 5 & 0,34 & 7 & 8 & 48,8 & 1 & 8 & 0,39 \\
\hline 6 & 7 & 33,0 & 5 & 6 & 0,30 & 7 & 9 & 37,6 & 3 & 8 & 0,38 \\
\hline 5 & 6 & 26,5 & 2 & 5 & 0,23 & 3 & 7 & 32,7 & 7 & 8 & 0,27 \\
\hline 3 & 5 & 20,7 & 6 & 10 & 0,17 & 1 & 7 & 23,8 & 1 & 3 & 0,17 \\
\hline 2 & 7 & 15,5 & 2 & 7 & 0,13 & 3 & 8 & 23,1 & 8 & 9 & 0,15 \\
\hline 2 & 5 & 14,4 & 5 & 10 & 0,09 & 1 & 8 & 22,9 & 3 & 7 & 0,14 \\
\hline 5 & 10 & 13,4 & 2 & 3 & 0,04 & 8 & 9 & 11,3 & 1 & 7 & $-0,03$ \\
\hline 3 & 6 & 11,7 & 2 & 10 & 0,02 & 1 & 3 & 9,2 & 3 & 9 & $-0,06$ \\
\hline 2 & 6 & 11,5 & 3 & 6 & $-0,07$ & - & - & - & - & - & - \\
\hline 5 & 7 & 11,0 & 6 & 7 & $-0,09$ & - & - & - & - & - & - \\
\hline 2 & 10 & 3,6 & 5 & 7 & $-0,10$ & - & - & - & - & - & - \\
\hline 2 & 3 & 2,1 & 2 & 6 & $-0,11$ & - & - & - & - & - & - \\
\hline 3 & 7 & 0,0 & 7 & 10 & $-0,29$ & - & - & - & - & - & - \\
\hline 7 & 10 & 0,0 & 3 & 7 & $-0,33$ & - & - & - & - & - & - \\
\hline \multicolumn{12}{|c|}{ Safra 2004} \\
\hline 2 & 6 & 56,2 & 2 & 11 & 0,46 & 3 & 4 & 64,8 & 4 & 5 & $0,66^{* *}$ \\
\hline 3 & 6 & 38,1 & 3 & 11 & 0,46 & 3 & 5 & 57,1 & 3 & 5 & $0,55^{*}$ \\
\hline 4 & 6 & 36,3 & 1 & 11 & 0,44 & 4 & 5 & 45,6 & 3 & 4 & $0,52^{*}$ \\
\hline 1 & 2 & 36,1 & 3 & 4 & 0,43 & 3 & 7 & 33,8 & 3 & 7 & 0,37 \\
\hline 2 & 11 & 31,8 & 4 & 11 & 0,39 & 2 & 3 & 28,6 & 3 & 6 & 0,35 \\
\hline 1 & 11 & 29,3 & 2 & 6 & 0,38 & 2 & 6 & 26,6 & 2 & 6 & 0,33 \\
\hline 3 & 11 & 29,2 & 1 & 2 & 0,37 & 3 & 6 & 25,2 & 1 & 5 & 0,30 \\
\hline 4 & 11 & 26,4 & 2 & 3 & 0,33 & 1 & 3 & 24,6 & 1 & 2 & 0,29 \\
\hline 3 & 4 & 25,2 & 7 & 11 & 0,30 & 1 & 5 & 21,1 & 1 & 3 & 0,28 \\
\hline 1 & 6 & 24,8 & 1 & 6 & 0,29 & 4 & 7 & 20,2 & 4 & 7 & 0,20 \\
\hline 6 & 11 & 24,3 & 1 & 3 & 0,24 & 1 & 2 & 20,0 & 6 & 7 & 0,20 \\
\hline 1 & 3 & 23,6 & 3 & 7 & 0,23 & 1 & 4 & 18,1 & 2 & 3 & 0,14 \\
\hline 1 & 4 & 21,0 & 3 & 6 & 0,16 & 4 & 6 & 12,0 & 5 & 7 & 0,12 \\
\hline 2 & 3 & 18,7 & 1 & 4 & 0,14 & 6 & 7 & 12,0 & 2 & 7 & 0,12 \\
\hline 7 & 11 & 16,1 & 6 & 11 & 0,09 & 5 & 7 & 8,7 & 1 & 4 & 0,12 \\
\hline 3 & 7 & 14,8 & 4 & 6 & 0,06 & 2 & 7 & 8,4 & 2 & 5 & 0,11 \\
\hline 2 & 4 & 1,1 & 2 & 4 & 0,02 & 2 & 4 & 7,5 & 2 & 4 & 0,10 \\
\hline 1 & 7 & 0,5 & 1 & 7 & $-0,05$ & 2 & 5 & 5,5 & 4 & 6 & $-0,07$ \\
\hline 4 & 7 & 0,0 & 4 & 7 & $-0,08$ & 5 & 6 & 0,0 & 1 & 6 & $-0,13$ \\
\hline 6 & 7 & 0,0 & 2 & 7 & $-0,31$ & 1 & 6 & 0,0 & 1 & 7 & $-0,24$ \\
\hline 2 & 7 & 0,0 & 6 & 7 & $-0,40$ & 1 & 7 & 0,0 & 5 & 6 & $-0,25$ \\
\hline
\end{tabular}

${ }^{(1)}$ Locais: 1, Anápolis, GO; 2, Santo Antônio de Goiás, GO; 3, Rio Verde, GO; 4, Morrinhos, GO; 5, Urutaí, GO; 6, Cristalina, GO; 7, Planaltina, DF; 8, Ipameri, GO; 9, Formosa, GO; 10, Goiatuba, GO; e 11, Itumbiara, GO. *e**Correlação significativa a 1 e 5\% de probabilidade, respectivamente. 
outra, é comum e ocorre em razão da dificuldade de manutenção de parcerias duradouras para a avaliação de genótipos de feijoeiro-comum e, também, em razão de perdas ocasionais de ensaios, principalmente na época das águas, em conseqüência do excesso de chuva na região.

Planaltina e Rio Verde estiveram presentes nas quatro safras, e sempre foram classificados como informativos, o que confirma que são importantes na avaliação de genótipos de feijoeiro-comum. Outros locais importantes foram: Santo Antônio de Goiás, Anápolis e Cristalina, onde se obtiveram resultados de ensaios em três das quatro safras avaliadas. Entre esses, Santo Antônio de Goiás e Anápolis foram pouco informativos em uma das safras, e Cristalina foi sempre um local informativo. Assim, pode-se inferir que os principais locais, onde ocorrem avaliações constantemente, são informativos.

A interação complexa representou, em média, 79\% do total, e a correlação média foi de 0,17 , o que reforça a existência de grandes diferenças entre os locais avaliados (Tabela 4). Esses valores são semelhantes aos relatados em outros estudos (Pacheco et al., 2008). Considerando-se os locais, dois a dois, em cada safra, $94 \%$ dos pares mostraram alta percentagem da interação atribuída à parte complexa, e $92 \%$ de baixa correlação de Pearson (Tabela 4). Isso também confirma a presença da interação GxA e a necessidade de avaliação das linhagens em vários locais. Outros trabalhos realizados consideraram ensaios de várias safras em uma só análise. Mendonça et al. (2007) trabalharam com soja, nos Estados do Paraná e Santa Catarina, e encontraram 92\% dos pares com predominância de interação complexa e 90\% com baixa correlação de
Pearson. Garbuglio et al. (2007) trabalharam com milho, nos mesmos estados, e encontraram $87 \%$ dos pares de ambientes com predominância de interação complexa e 56\% com baixa correlação de Pearson. Pacheco et al. (2008), também em pesquisa com milho, encontraram $100 \%$ dos pares com predominância da interação complexa e $87 \%$ de correlações baixas.

Com relação à comparação de metodologias de estratificação ambiental, Oliveira et al. (2005) relataram que os métodos da correlação de Pearson e da percentagem simples da interação genótipos $\mathrm{x}$ ambientes não agregaram informações ao método tradicional de Lin. No presente trabalho, para comparar os métodos utilizados, observou-se quantas vezes o local menos informativo (Anápolis, águas/2003; Urutaí, águas/2004; Goiatuba, inverno/2003; e Santo Antônio de Goiás, inverno/2004) foi identificado em cada um dos métodos. Métodos que identificaram o local menos informativo mais vezes, nas diferentes safras, foram considerados mais eficientes. Nas safras das águas/2003 e das águas/2004, os quatro métodos identificaram Anápolis e Urutaí como pouco informativos, nas respectivas safras. $\mathrm{Na}$ safra de inverno/2003, o método da percentagem simples da interação GxA não identificou Goiatuba no par de locais menos informativos, enquanto os outros três métodos sim. Na safra do inverno/2004, somente o método da correlação de Pearson não identificou Santo Antônio de Goiás no par de locais menos informativos. Assim, o método tradicional de Lin e o da ecovalência foram os mais eficientes, pois sempre identificaram os locais menos informativos, e devem ser, consequentemente, os mais indicados para estudos dessa natureza.

Tabela 5. Estimativas de ecovalência (W), para os locais onde foram conduzidos ensaios com genótipos de feijoeiro-comum, nas duas épocas de semeadura em 2003 e 2004, no Estado de Goiás e no Distrito Federal.

\begin{tabular}{|c|c|c|c|c|c|c|c|c|}
\hline \multirow[t]{3}{*}{ Local } & \multicolumn{4}{|c|}{ Inverno } & \multicolumn{4}{|c|}{ Águas } \\
\hline & \multicolumn{2}{|c|}{2003} & \multicolumn{2}{|c|}{2004} & \multicolumn{2}{|c|}{2003} & \multicolumn{2}{|c|}{2004} \\
\hline & $\mathrm{W}\left(\mathrm{x} 10^{3}\right)$ & $(\%)$ & $\mathrm{W}\left(\mathrm{x} 10^{3}\right)$ & $(\%)$ & $\mathrm{W}\left(\mathrm{x} 10^{3}\right)$ & $(\%)$ & $\mathrm{W}\left(\mathrm{x} 10^{3}\right)$ & $(\%)$ \\
\hline Planaltina, DF & 5.238 & 12 & 6.368 & 18 & 2.692 & 16 & 4.942 & 14 \\
\hline Anápolis, GO & - & - & 4.992 & 14 & 1.502 & 8 & 6.046 & 18 \\
\hline Santo Antônio de Goiás, GO & 6.219 & 14 & 2.021 & 6 & - & - & 3.306 & 10 \\
\hline Rio Verde, GO & 5.856 & 13 & 1.968 & 6 & 4.056 & 22 & 8.168 & 24 \\
\hline Itumbiara, GO & - & - & 2.406 & 7 & - & - & - & - \\
\hline Morrinhos, GO & - & - & 2.786 & 8 & - & - & 2.031 & 6 \\
\hline Cristalina, GO & 17.381 & 39 & 14.196 & 41 & - & - & 6.996 & 20 \\
\hline Ipameri, GO & - & - & - & - & 3.750 & 20 & - & - \\
\hline Formosa, GO & - & - & - & - & 6.300 & 34 & - & - \\
\hline Goiatuba, GO & 3.596 & 8 & - & - & - & - & - & - \\
\hline Urutaí, GO & 5.775 & 14 & - & - & - & - & 2.785 & 8 \\
\hline Total & 44.065 & 100 & 34.737 & 100 & 18.300 & 100 & 34.274 & 100 \\
\hline
\end{tabular}

Pesq. agropec. bras., Brasília, v.45, n.6, p.554-562, jun. 2010 
A correlação de Pearson, obtida entre a média dos locais e a estimativa de ecovalência em cada safra, foi significativa apenas na safra de inverno/2003 (0,84*). Em geral, as correlações foram não significativas $(-0,02$, nas águas/2003; 0,35, nas águas/2004; e 0,17 , no inverno/2004), o que indica que a análise de ecovalência agrega informação útil para a identificação de locais pouco informativos.

\section{Conclusões}

1. Entre os locais avaliados em pelo menos três das quatro safras, Rio Verde, Planaltina e Cristalina são informativos e indicados para a avaliação de genótipos de feijoeiro-comum do tipo Carioca, no Estado de Goiás e no Distrito Federal.

2. Os métodos tradicional de Lin e ecovalência de Wricke são os mais indicados para identificação de locais pouco informativos, na avaliação de genótipos de feijoeiro-comum tipo Carioca.

\section{Agradecimentos}

À Embrapa Arroz e Feijão, à Embrapa Cerrados, ao Centro Federal de Educação e Tecnologia de Urutaí e de Morrinhos, ao Instituto Luterano de Ensino/ Universidade Luterana do Brasil e à Secretaria de Agricultura, Pecuária e Abastecimento do Estado de Goiás (escritórios de Anápolis e Rio Verde), pela parceria na condução dos ensaios.

\section{Referências}

BERTOLDO, J.G.; COIMBRA, J.L.M.; NODARI, B.O.; GUIDOLIN, A.F.; HEMP, S.; BARILI, L.D.; VALE, N.M.; ROZZETO, D.S. Stratification of the state of Santa Catarina in macro-environments for bean cultivation. Crop Breeding and Applied Biotechnology, v.9, p.335-343, 2009.

BRASIL. Instrução Normativa $n^{\circ} 25$, de 23 de maio de 2006. Estabelece os critérios mínimos a serem observados para a determinação do valor de cultivo e uso - VCU de feijão e os respectivos formulários anexos para inscrição de cultivares no Registro Nacional de Cultivares. Anexo I. Requisitos mínimos para determinação do valor de cultivo e uso de feijão (Phaseolus vulgaris) para a inscrição no Registro Nacional de Cultivares RNC. Diário Oficial [da] República Federativa do Brasil, 19 jun. 2006. Seção 1, p.16.

CARBONELL, S.A.M.; AZEVEDO FILHO, J.A. de; DIAS, L.A. dos S.; GARCIA, A.A.F.; MORAIS, L.K. de. Common bean cultivars and line interactions with environments. Scientia Agricola, v.61, p.169-177, 2004.
CARBONELL, S.A.M.; POMPEU, A.S. Estratificação de ambientes em experimentos de feijoeiro no Estado de São Paulo. Bragantia, v.56, p.207-218, 1997.

COCHRAN, W.G. The combination of estimates from different experiments. Biometrics, v.10, p.101-129, 1954.

CRUZ, C.D. Programa Genes: aplicativo computacional em genética e estatística: versão Windows. Viçosa: UFV, 2001. 648p.

CRUZ, C.D.; CASTOLDI, F. Decomposição da interação genótipos $\mathrm{x}$ ambientes em partes simples e complexa. Revista Ceres, v.38, p.422-430, 1991.

CRUZ, C.D.; REGAZZI, A.J. Modelos biométricos aplicados ao melhoramento genético. Viçosa: UFV, 2001. 390p.

FEIJÃO: dados de conjuntura da produção de feijão (Phaseolus vulgaris L.) e caupi (Vigna unguiculata (L.) Walp) no Brasil: 1985 - 2008. Disponível em: < http://www.cnpaf.embrapa.br/apps/ socioeconomia/index.htm>. Acesso em: 20 mar. 2010.

GARBUGLIO, D.D.; GERAGE, A.C.; ARAÚJO, P.M. de; FONSECA JÚNIOR, N. da S.; SHIOGA, P.S. Análise de fatores e regressão bissegmentada em estudos de estratificação ambiental e adaptabilidade em milho. Pesquisa Agropecuária Brasileira, v.42, p.183-191, 2007.

GOMES, F.P. Curso de estatística experimental. 14.ed. São Paulo: Nobel, 2000. 466p.

LIN, C.S. Grouping genotypes by a cluster method directly related to genotype-environment interaction mean-square. Theoretical and Applied Genetics, v.62, p.277-280, 1982.

MELO, L.C.; DEL PELOSO, M.J.; FARIA, J.C. de; YOKOYAMA, M.; ROSARIA, L.; BRONDANI, R.P.V.; BRONDANI, C.; FARIA, L.C. de. Controle genético da reação do feijoeiro-comum ao vírus do mosaico-dourado. Santo Antônio de Goiás: Embrapa Arroz e Feijão, 2005. 16p. (Embrapa Arroz e Feijão. Boletim de Pesquisa e Desenvolvimento, 15).

MELO, L.C.; MELO, P.G.S.; FARIA, L.C. de; DIAZ, J.L.C.; DEL PELOSO, M.J.; RAVA, C.A.; COSTA, J.G.C. da. Interação com ambientes e estabilidade de genótipos de feijoeiro-comum na Região Centro-Sul do Brasil. Pesquisa Agropecuária Brasileira, v.42, p.715-723, 2007.

MENDONÇA, O.; CARPENTIERI-PÍPOLO, V.; GARBUGLIO, D.D.;FONSECAJUNIOR, N. da S. Análise de fatores e estratificação ambiental na avaliação da adaptabilidade e estabilidade em soja. Pesquisa Agropecuária Brasileira, v.42, p.1567-1575, 2007.

MURAKAMI, D.M.; CRUZ, C.D. Proposal of methodologies for environment stratification and analysis of genotype adaptability. Crop Breeding and Applied Biotechnology, v.4, p.7-11, 2004.

OLIVEIRA, G.V. de; CARNEIRO, P.C. de S.; DIAS, L.A. dos S.; CARNEIRO, J.E. de S.; CRUZ, C.D. Factor analysis in the environment stratification for the evaluation of common bean cultivars. Crop Breeding and Applied Biotechnology, v.5, p.166-173, 2005.

PACHECO, C.A.P.; SILVA, H.D.; SANTOS, M.X. dos; GUIMARÃES, P.E. de O.; PARENTONI, S.N.; GAMA; E.E.G. e; SCAPIM, C.A.; MEIRELLES, W.F.; CARVALHO, H.W.L. de; VIEIRA JUNIOR, P.A. Environmental stratification based on a 28 
x 28 diallel of open-pollinated maize varieties. Crop Breeding and Apllied Biotechnology, v.8, p.259-264, 2008.

PEREIRA, H.S.; MELO, L.C.; FARIA, L.C. de; DEL PELOSO, M.J.; COSTA, J.G.C. da; RAVA, C.A.; WENDLAND, A. Adaptabilidade e estabilidade de genótipos de feijoeiro-comum com grãos tipo carioca na Região Central do Brasil. Pesquisa Agropecuária Brasileira, v.44, p.29-37, 2009.

WRICKE, G. Zur Berechnung der Ökovalenz bei Sommerweizen und Hafer. Zeitschrift für Pflanzenzüchtung, v.52, p.127-138, 1965.

Recebido em 24 de março de 2010 e aprovado em 14 de maio de 2010 